\title{
As trabalhadoras da limpeza de uma instituição pública de ensino superior: gênero, terceirização e precarização
}

Gabriella Ane Dresch ${ }^{1}$

Lincoln Renato Vieira Zanardine ${ }^{2}$

Stéphanie Faux ${ }^{3}$

Resumo: Esse artigo é parte de uma pesquisa realizada com as trabalhadoras da limpeza do campus Reitoria da Universidade Federal do Paraná durante o primeiro semestre de 2014. Através da análise sociológica de um questionário aplicado a 21 trabalhadoras, elencou-se um debate sobre questão do gênero na profissão delas, explorado sob diversas perspectivas, como a bipolaridade da inserção da mulher no mercado de trabalho e as noções de masculino e feminino trazidas por elas e a relação com a esfera privada. A discussão se amplia, e, neste contexto, está atrelada à terceirização e à precarização do trabalho. Para tanto, é apresentado panorama do funcionamento deste emprego, seguido do perfil das funcionárias, bem como o conceito da divisão sexual do trabalho mesclado às experiências relatadas e às concepções observadas nos discursos das funcionárias.

Palavras chave: trabalhadoras da limpeza, terceirização, relações de gênero, trabalho.

\footnotetext{
${ }^{1}$ Graduanda do curso de Ciências Sociais da Universidade Federal do Paraná (UFPR). Contato: gadresch@gmail.com

${ }^{2}$ Graduando do curso de Ciências Sociais da Universidade Federal do Paraná (UFPR). Contato: lincolnzanardine@yahoo.com

${ }^{3}$ Graduanda do curso de Antropologia da Université Catholique de Louvain (UCL). Contato: faux.stephanie@gmail.com
} 
Abstract: This article is part of a survey on janitors working at the Rectory of the University Federal of Paraná campus, during the first half of 2014. Through sociological analysis of a questionnaire administered to 21 workers, one can raise a debate on gender issues related to the profession and analyze them from various perspectives, such as: bipolarity of women entering the labor market, the notions of masculinity and femininity, and the relationship with the private sphere. The discussion goes further, and in this context, is linked to the outsourcing and the precarious job. Therefore, one will present an overview of the working conditions of this profession, followed by the profile of the janitors, the concept of the sexual division of labor mixing the related experiences, and concepts observed in the discourses of the janitors.

Keywords: Cleaning workers, janitors, outsourcing, gender relations, work.

\section{Introdução}

Este artigo é um recorte de uma pesquisa ${ }^{4}$ sobre as trabalhadoras da limpeza da Reitoria ${ }^{5}$ UFPR, realizada durante o primeiro semestre de 2014. A ideia desta pesquisa surgiu do interesse

\footnotetext{
4 A pesquisa teve início a partir da proposta de uma disciplina de graduação denominada "Trabalho e Desigualdade Social".

${ }^{5}$ O Campus Reitoria abriga o Setor de Ciências Humanas, Letras e Artes, o Setor de Educação e o departamento de Design. Está localizado na região central de Curitiba. É composto pelos edifícios Dom Pedro I, de doze andares e Dom Pedro Segundo, de sete andares. Além disso, há o prédio da Reitoria, o Teatro Reitoria, a Biblioteca Central e um dos Restaurantes Universitários da UFPR. O HC fica na região do campus, mas o seu sistema de limpeza é diferente, portanto não foi incluído.
} 
de analisar sociologicamente o trabalho das pessoas responsáveis por pela limpeza da UFPR, em virtude dos contrastes que essa profissão traz quando inserida na universidade. As trabalhadoras da limpeza estão invariavelmente presentes em toda a universidade, no entanto não estão de fato nela. Elas não participam das atividades relacionadas aos estudos e, conforme essa pesquisa demonstrou os seus filhos também não aparecem nesse meio enquanto estudantes. Esse campus foi escolhido por ser o local que frequentamos enquanto estudantes de Ciências Sociais e, portanto, onde as encontramos com maior facilidade e as observamos cotidianamente.

$\mathrm{O}$ trabalho de uma pessoa cuja profissão se relaciona com a limpeza pode ser analisado sobre diversas perspectivas. Neste estudo, optamos inicialmente por explorar a questão do estigma, pois a nossa hipótese era de que tal elemento teria destaque na fala das funcionárias. Uma vez em campo, no entanto, nos deparamos com outras questões que se sobressaíram. Esse artigo diz respeito a um aspecto que teve grande destaque e que de modo algum poderia ser ignorado: a relação entre gênero e trabalho. Para tanto, foram utilizadas autoras e autores como Hirata e Kergoat (2007), Araújo (2007) e Souza (2011). A ferramenta metodológica consistiu na aplicação de um questionário que será descrito nos tópicos subsequentes. As respostas que nos foram cedidas, a experiência de conversar com essas mulheres e de frequentar seu ambiente de trabalho através de outro ponto de vista, deu base para importantes reflexões colocadas nessa pesquisa. 
$\mathrm{O}$ artigo está estruturado da seguinte maneira: inicialmente, apresentaremos algumas informações importantes acerca do trabalho das serventes de limpeza, como o salário, a rotina e a distribuição das funcionárias pelos prédios. A partir delas, há uma explanação sobre a metodologia adotada. Na sequência, descrevemos o perfil das mulheres que participaram da pesquisa, para então introduzirmos o conceito da divisão sexual do trabalho. Deste modo, podemos entrar em uma discussão sobre as continuidades e rupturas das esferas pública e privada e a posição das mulheres nesse mercado de trabalho. Por fim, abordamos a terceirização e precarização do trabalho de servente de limpeza, sem deixar de adotar a perspectiva do gênero, pois entendemos que nenhum dos elementos aparece isoladamente, nem pode ser compreendido isoladamente.

\section{A delimitação do campo e os primeiros dados}

Quando nos propusemos a analisar a situação do trabalho das serventes de limpeza na UFPR, inicialmente buscamos contato com uma interlocutora da equipe do campus da Reitoria. Tivemos uma conversa com ela, da qual obtivemos uma série de informações: o serviço de limpeza era terceirizado e o salário das funcionárias era de $\mathrm{R}$ \$: 803,00 mais um adicional de $\mathrm{R} \$ 43,00$ pela assiduidade, além do vale transporte e R $\$ 248,00$ de vale alimentação. Quem trabalhava no Restaurante Universitário recebia o valor de $\mathrm{R} \$$ : 850,00 e não pagava 
pelas refeições. No entanto, de acordo com as trabalhadoras, há uma grande quantidade de descontos salariais, geralmente por faltas e outros motivos que não foram citados.

Havia dois turnos de trabalho: o primeiro era das 06:30 horas da manhã até às 14:30, com pausa de uma hora para o almoço. $O$ segundo turno tinha início às 14:30 e encerrava às 22:30, também com pausa de uma hora. No momento da pesquisa, havia um total de quarenta e nove profissionais da limpeza no campus Reitoria; apenas um era homem. Elas estão distribuídas da seguinte forma: treze no edifício D. Pedro I, cinco no edifício D. Pedro II, duas no Teatro da Reitoria, três no Prédio Reitoria, quatorze no Restaurante Universitário, duas na Biblioteca Central, uma na Casa da Estudante Universitária de Curitiba (CEUC), uma no DSG (Departamento de Serviços Gerais), duas na cobertura de faltas e duas de férias.

Formalmente, o critério para a contratação das funcionárias era ter ficado pelo menos durante um ano em outra empresa, não havendo menção ao nível de escolaridade, idade ou gênero. Não havia circulação das funcionárias entre os campi da UFPR, cada trabalhadora era responsável por determinada parte de cada prédio.

Uma vez em posse desses dados, optamos por elaborar um questionário dividido em três blocos principais, com perguntas abertas e fechadas. Conscientes de que um questionário elenca uma riqueza de detalhes menor do que as entrevistas de profundidade, procuramos suprir um pouco desta falta deixando uma abertura para que, em 
determinados momentos, elas pudessem explorar mais os assuntos conforme desejassem.

O primeiro bloco buscava identificar o perfil das funcionárias, incluindo, portanto, a escolaridade, a idade, o estado civil e similaridades. O segundo bloco consistia no mapeamento do histórico de trabalho delas e nas impressões acerca de sua profissão. Como o foco inicial era a questão do estigma, grande parte das questões foi pensada de modo perceber essa possível situação. No entanto, identificamos muitos elementos ricos para um estudo de gênero, que serão debatidos nos tópicos seguintes. Por fim, o terceiro bloco se referia à condição socioeconômica.

O interesse da pesquisa se concentrava, a princípio, na relação cotidiana entre trabalhadoras da limpeza e os demais frequentadores da universidade no ambiente acadêmico e de circulação deles. Por esse motivo, decidimos não trabalhar com as funcionárias da CEUC, Biblioteca Central e Teatro da Reitoria. Nesses lugares, havia pouco ou nenhum contato entre as pessoas citadas, ou elas estavam em um ambiente que não correspondia ao contexto pretendido para fins de análise. Quanto às funcionárias do Restaurante Universitário, além de também não estarem totalmente englobadas no contexto pretendido, não foi possível realizar uma pesquisa com elas, uma vez que o RU estava em greve no momento da coleta de dados. O único homem citado trabalhava no RU, e, recentemente, descobrimos que o mesmo havia sido demitido; ficando fora do universo da pesquisa. Por essa razão, este 
estudo envolve somente mulheres. Após a delimitação, iniciamos a coleta de dados com todas as funcionárias do D. Pedro I, D. Pedro II e prédio da Reitoria.

A aplicação do questionário se deu entre os dias 10/04/2014 e 30/04/2014. Embora as repostas tenham sido anônimas, uma das trabalhadoras se recusou a responder.

\section{Quem são as trabalhadoras da limpeza da Reitoria UFPR?}

Antes de adentrar as discussões propostas por esse artigo, julgamos importante apresentar o perfil das mulheres que fizeram parte da pesquisa, com o intuito de situar os leitores e as leitoras.

As funcionárias com as quais trabalhamos tinham idades que variavam entre 26 e 62 anos, sendo que $38 \%$ delas estavam na faixa de 40 a 49 anos.

Idade

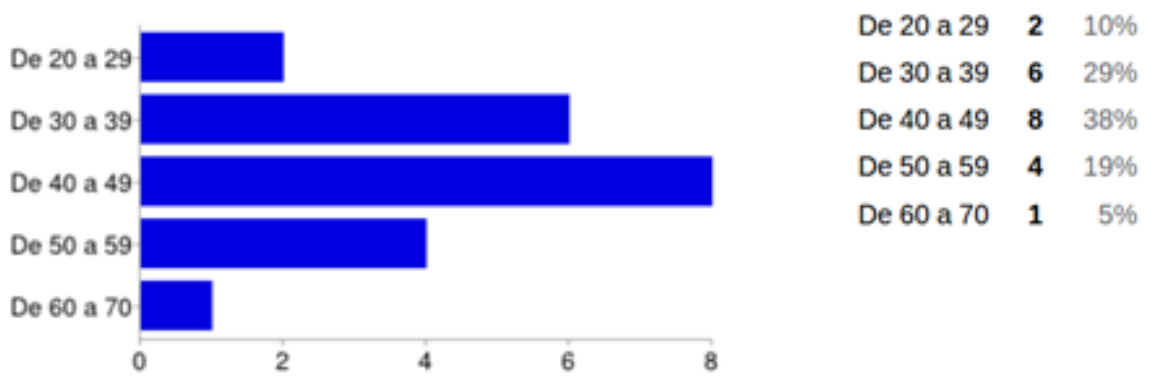


Três delas nasceram em Curitiba, quatro nasceram em outros estados e as demais vieram da região metropolitana ou do interior do Paraná. No momento do questionário, dezenove funcionárias moravam na região metropolitana de Curitiba, a maioria delas em Colombo e em Piraquara, como mostra o gráfico a seguir:

\section{Onde você mora?}

Almirante Tamandaré

Araucária

Colombo

Curitiba/ Bairro

Curitiba/ Vila Sa..

Fazenda Rio Grande

Itaperuçu

Piraquara

Rio Branco do Sul-

$\begin{array}{lllllll}0 & 1 & 2 & 3 & 4 & 5 & 6\end{array}$
Almirante Tamandaré $\quad \mathbf{0} \quad 0 \%$

Araucária

Colombo $629 \%$

Curitiba/ Bairro alto $\quad 2 \quad 10 \%$

Curitiba/Vila Sandra $1 \quad 5 \%$

Fazenda Rio Grande $\quad 2 \quad 10 \%$

Itaperuçu $\quad 2 \quad 10 \%$

$\begin{array}{lll}\text { Piraquara } & 6 & 29 \%\end{array}$

Rio Branco do Sul $15 \%$

Sobre a escolaridade, quinze mulheres disseram ter o ensino fundamental incompleto, uma funcionária não era alfabetizada e uma tinha graduação em pedagogia. As demais se situavam entre ensino fundamental completo e ensino médio completo. Consideramos que a funcionária graduada era uma outsider, pois sua trajetória diferia 
consideravelmente das demais trabalhadoras que participaram do questionário, bem como das pesquisas que lemos sobre o tema.

\section{Escolaridade}

Não Alfabetizada

Fundamental incom...

Fundamental completo

Médio Incompleto

Médio Completo

Graduaçằ

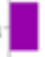

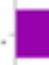

\section{西}
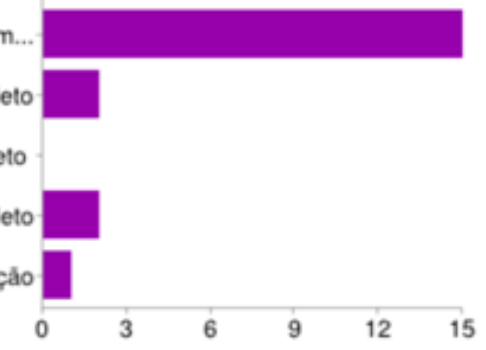

Não Alfabetizada

Fundamental incompleto

Fundamental completo

Médio Incompleto

Médio Completo

Graduação
$15 \%$

$1571 \%$

$210 \%$

o $0 \%$

$210 \%$

$15 \%$

A respeito das famílias, a quantidade de pessoas que moram na mesma casa variou entre 1 e 10 pessoas; a maior parte era composta por 4 pessoas (29\%). Todas elas tinham entre um e cinco filhos ou filhas, sendo que eles possuíam a escolaridade um pouco mais elevada que a das mães. De um total de sessenta filhos e filhas, oito estavam na série correta para a idade, três cursavam o ensino técnico e quatro frequentavam uma faculdade. Muitos pararam de estudar no ensino fundamental ou no ensino médio. 


\section{Quantos filhos/as você tem?}

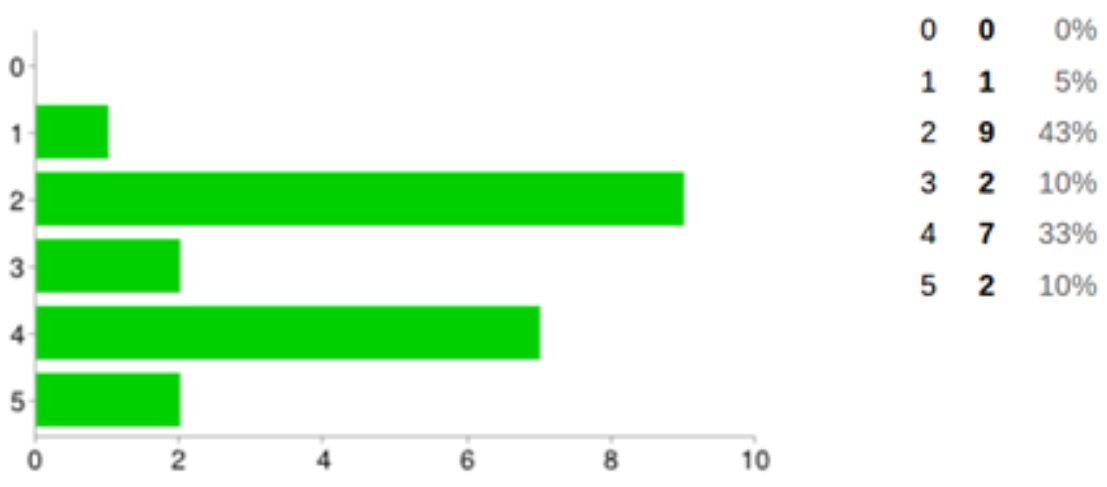

Mais da metade das respondentes estava casada ou em um relacionamento estável, além disso, havia duas viúvas, três divorciadas e três solteiras.

O conjunto dessas informações vai de encontro à pesquisa de Bruschini e Lombardi (2001) sobre o trabalho feminino no fim do século XX, na qual elas descrevem uma mudança no perfil das trabalhadoras brasileiras. Segundo as autoras, as trabalhadoras até o fim dos anos setenta eram predominantemente jovens, solteiras e sem filhos. Já a partir dos anos oitenta, a maioria delas passa a ser casada, tem filhos e é mais velha (BRUSCHINI e LOMBARDI, p. 163, 2001).

Durante a aplicação do questionário, o relato de uma das viúvas chamou a atenção, pois ela justificava seu emprego pela necessidade de ter relações sociais. Segundo Maria ${ }^{6}$, após a morte do esposo ela ficou muito sozinha em casa. Maria disse não precisar do

\footnotetext{
${ }^{6}$ Todos os nomes que aparecem no texto são fictícios para preservar a identidade das respondentes.
} 
salário, trabalhava porque isso a fazia bem e ela gostava de ter contato com outras pessoas. Houve outro caso similar, no qual a irmã de uma funcionária havia falecido. Observamos que ambas não tinham críticas em relação às condições de trabalho. Embora duas pessoas não seja um número elevado, considerando que o universo da pesquisa é pequeno, julgamos o dado significativo. Além disso, esses casos vêm em sintonia com outra informação: sete trabalhadoras disseram que o que mais gostavam na profissão era a amizade com as colegas, foi a resposta mais citada, seguida da limpeza em si e do ambiente do trabalho.

Em relação às características étnico-raciais, oito se declararam brancas, dez se disseram pardas, uma era indígena e duas se declararam amarelas. Nenhuma funcionária se declarou negra. Esse foi um dado diferente do apresentado pela pesquisa de Chaves (2014), também sobre funcionárias terceirizadas de uma instituição de ensino federal: seu artigo apontava que a maioria das trabalhadoras da área de limpeza era negra. A autora buscou esclarecer como a terceirização causava um sofrimento emocional às trabalhadoras e também considera que elas sofriam mais devido à condição socialmente imposta por conta da cor da sua pele. Para explicar essa condição, Chaves fez um apanhado histórico da formação do capitalismo no Brasil e da utilização da força de trabalho negra. Na época da escravidão, as escravas e escravos domésticos eram responsáveis pela manutenção da casa das famílias brancas; "suas atividades eram diretamente vinculadas ao serviço doméstico: lavadeiras, cozinheiras, amas de leite, aias, cocheiros, entre 
outras" (CHAVES, 2014, p. 4). Ela salienta que após a abolição da escravatura, as mulheres negras continuaram a exercer o serviço doméstico.

Entendemos que esse dado exige uma análise complexa para ser compreendido em uma possível continuidade da pesquisa, especialmente porque o Paraná tem características singulares no que tange as questões étnico-raciais. A discussão envolveria os contextos históricos, as questões de identificação, de preconceitos e vários outros elementos ligadas ao tema. Como este não era o foco, cabe apenas mencionar que, ainda que a quantidade de trabalhadoras que se autodeclararam negras e pardas não seja elevada como na pesquisa de Chaves (2014), verificamos através do censo $2010^{7}$ que $71,3 \%$ da população do Paraná se declarou branca; 2,9\% se declarou negra, 24, $5 \%$ é parda e 1,3\% se disse amarela ou indígena. Na Reitoria UFPR, a quantidade de trabalhadoras que se declararam pardas foi praticamente o dobro proporcionalmente à população do Paraná. 
Você se declara:

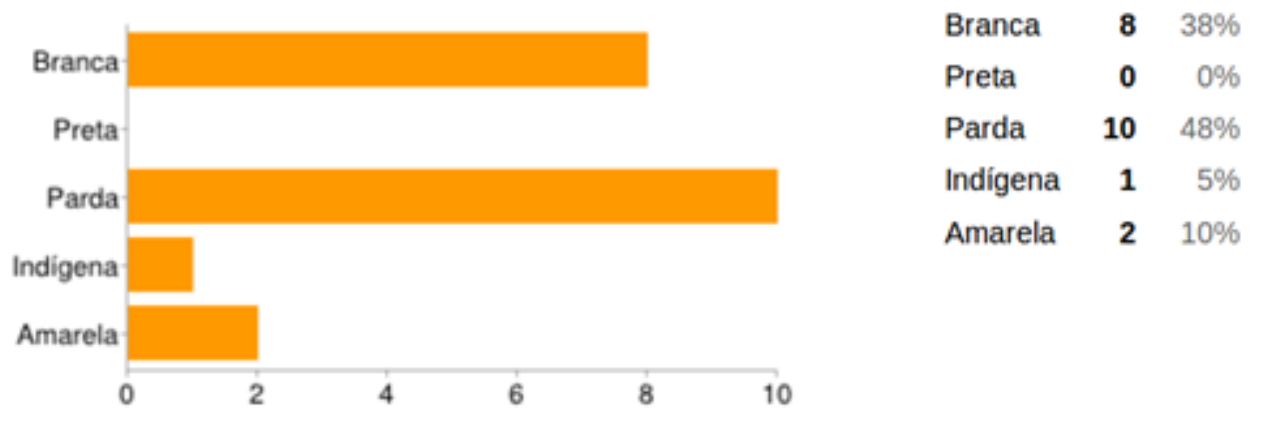

Sobre o histórico profissional, por fim, quinze respondentes afirmaram que trabalharam principalmente com carteira assinada ao longo da vida, dessas, sete trabalharam a maior parte do tempo com limpeza e oito em outras áreas, como auxiliares de cozinha, vendedoras, entre outros. Somente três funcionárias trabalhavam na UFPR há cinco anos ou mais.

O gênero aparece: os homens não estão com nada!

Conforme descrevemos, um dos primeiros contatos que tivemos foi com uma interlocutora da zeladoria da Reitoria UFPR. A partir da conversa com ela, a questão do gênero apareceu e teve grande destaque. Afinal, o fato de que quarenta e oito das quarenta e nove pessoas que trabalhavam com a limpeza eram mulheres, não poderia ser ignorado. Esse dado foi o ponto de partida para as reflexões que 
compõem esse artigo, desde o discurso de Carmem, nossa principal interlocutora, até as informações apresentadas em campo.

De acordo com a interlocutora da pesquisa, ser mulher não era um critério utilizado pela empresa no processo da contratação das funcionárias; ela relata que havia inclusive duas vagas destinadas aos homens em virtude do trabalho braçal ser mais pesado, mas que não eram preenchidas. Carmem disse que às vezes alguns homens começavam o período de experiência, contudo não permaneciam posteriormente. Quando indagada sobre qual seria o motivo, ela respondeu: “os homens não estão com nada!”. Prosseguiu dizendo que, para ela, não havia homens ocupando as funções de limpeza porque "para um pai de família, é difícil conseguir com esse salário".

Tal afirmação nos deu margem para debater as noções de masculino e do feminino que apareceram nos discursos das serventes da limpeza, imagens que vêm junto com o processo de socialização. A concepção de "pai de família" aparece com frequência em estudos relacionados às trabalhadoras da limpeza, a dissertação de Souza (2011) é um exemplo:

$\mathrm{O}$ fato de muitas entrevistadas justificarem o grande número de mulheres nestas atividades pela remuneração e pela forma como a família é constituída apenas, evidencia como, no imaginário social, os estereótipos de gênero que associam a imagem da mulher a casa e a do homem ao papel de provedor, ainda permanecem. SOUZA, p. 73, 2011. 
Partindo dessa constatação, julgamos necessário entender melhor o conceito da divisão sexual do trabalho: como uma série de características são relacionadas ao corpo da pessoa e ao gênero dela e como isso tem um efeito nas relações sociais, inclusive nas atividades profissionais cada indivíduo. David Le Breton (2012) aponta: “O corpo metaforiza o social e o social metaforiza o corpo. No interior do corpo são as possibilidades sociais e culturais que se desenvolvem." (LE BRETON, p. 70, 2012).

\section{A divisão sexual do trabalho}

Para debater gênero e mercado de trabalho, entendemos ser essencial abordar divisão sexual do trabalho; termo utilizado por diversos autores e autoras. No caso deste artigo, utilizamos o conceito colocado por Hirata e Kergoat (2007):

A divisão sexual do trabalho é a forma de divisão do trabalho social decorrente das relações sociais entre os sexos; mais do que isso, é um fator prioritário para a sobrevivência da relação social entre os sexos. Essa forma é modulada histórica e socialmente. Tem como características a designação prioritária dos homens à esfera produtiva e das mulheres à esfera reprodutiva e, simultaneamente, a apropriação pelos homens das funções com maior valor social adicionado (políticos, religiosos, militares etc.). (HIRATA, KERGOAT, 2007, p. 5) 
É relevante explicar que embora as autoras se situem de teoricamente a partir dessa definição, elas julgam que somente esta não basta para explicar com a devida profundidade o conteúdo da divisão sexual do trabalho. Para elas, é preciso incluir dois princípios organizadores: o princípio da separação e o princípio hierárquico. O primeiro consiste basicamente no entendimento de que há trabalhos de homens e trabalhos de mulheres, enquanto o segundo percebe as diferenças de valores entre os trabalhos de homens e de mulheres, nos quais os dos homens valem mais (HIRATA, KERGOAT, 2007, p. 5). Elas reconhecem esse fenômeno em diversas sociedades ocidentais e destacam que a divisão não é estática, pois varia de acordo com o tempo e o contexto de cada época.

É possível estabelecer um ponto de convergência com Cláudia Mazzei Nogueira (2009), em seu estudo acerca das metamorfoses da divisão sexual do trabalho:

Ao refletir sobre a divisão sexual do trabalho, é possível afirmar que as atividades mais precárias estão reservadas para as mulheres, uma vez que a força de trabalho feminina encontra-se diretamente articulada às relações de poder presentes na histórica afirmação de que o trabalho da mulher tem menos valor do que o do homem em virtude, prioritariamente, de suas especificidades "naturais" de mãe e esposa. (NOGUEIRA, p. 63) 
Não obstante, Laís Abramo (2007) ressalta que a divisão sexual do trabalho e, por conseguinte, a atribuição de funções domésticas e da esfera privada à mulher, conciliadas com o trabalho assalariado, implica não apenas em menos tempo para investir na formação e na carreira, mas também é responsável por subvalorizar econômica e socialmente a atuação das mulheres na esfera pública.

Uma vez no mercado de trabalho, além de as mulheres continuarem exercendo atividades domésticas em casa, muitas das funções das quais são encarregadas estão ligadas às especificidades "naturais" atribuídas ao feminino, especificidades do âmbito privado. Atividades que incluem cozinhar, limpar, lavar e cuidar de crianças são predominantemente ocupadas por mulheres, o que ressalta a força da divisão sexual do trabalho. Não por acaso, o relato da maioria das participantes da pesquisa demonstra que elas começaram a trabalhar com a limpeza porque, segundo elas, a escolaridade baixa não thes permitiu conseguir outros empregos e limpar era o que já sabiam fazer; o que haviam aprendido em casa. As que já haviam tido outros empregos citaram, sobretudo, funções em cozinhas, trabalhos como diaristas e como babás. Não obstante, observamos que grande parte delas começou a trabalhar na UFPR por conta da indicação de amigas. Além disso, quando elas têm algum parente que também é da área da limpeza, essa pessoa é quase sempre mulher. Na pesquisa, $52 \%$ das mulheres afirmaram ter parentes trabalhando nessa área. Esse paradoxo 
das trabalhadoras em espaços públicos versus a continuidade da esfera privada fica claro no artigo de Ângela Maria Carneiro Araújo:

As mudanças no sistema de produção têm requerido das mulheres uma série de habilidades que, adquiridas através do seu processo de socialização no espaço privado, apelam para o reforço de comportamentos culturalmente definidos como femininos. (ARAÚJO apud Posthuma,1996, Rizek e Leite, 1998, Abramo, 1998, p. 4)

Daniele Kergoat reforça essa constatação: "se de um lado há um deslocamento das linhas de tensão, de outro, as relações sociais de sexo permanecem intactas." (KERGOAT, 2010, p. 95).

Historicamente, as mulheres tiveram menos espaço e direitos que os homens, mas é falha a ideia de que só há algumas décadas elas tiveram sua inserção no mercado de trabalho. As mulheres de estratos sociais mais baixos sempre exerceram atividades para ter ou complementar a renda de sua casa; nesse sentido, é possível dizer que ao longo dos anos mais mulheres passaram adentrar o mercado de trabalho. Ricardo Antunes (1999) aponta que houve uma expansão considerável do trabalho feminino nas últimas décadas, especialmente no trabalho mais precarizado. Para o autor, a ampliação do trabalho feminino tem sido parte de um processo de emancipação parcial das mulheres, em relação à sociedade de classes e também ao que tange as 
diversas formas de opressão masculina, baseadas na divisão social e sexual do trabalho. Se por um lado esse é um aspecto positivo, por outro, Antunes defende que "o capital incorpora o trabalho feminino de modo desigual e diferenciado em sua divisão social e sexual do trabalho". (ANTUNES, 1999, p. 109)

Partindo do contexto descrito e considerando que existem diferenças na inserção das mulheres no mercado de trabalho, Nanci S. Silva e Leda Maria C. Gitahy (2006) atentam para o que chamam de situação bipolar das mulheres no mercado de trabalho: em um dos polos estão as mulheres altamente qualificadas, com escolaridade elevada que ocupam novos espaços: cargos de engenheiras, de gerentes, de arquitetas, médicas, entre outros. No polo oposto estão as mulheres com baixa escolaridade, cujos trabalhos são desvalorizados socialmente, como as trabalhadoras domésticas (SILVA e GIATAHY, p.60, 2006). As trabalhadoras que fizeram parte desta pesquisa estão inseridas no segundo polo, pois não tinham qualificações formais e exerciam uma atividade desvalorizada e tradicionalmente associada ao feminino: a limpeza.

Intrinsecamente relacionado ao debate da divisão sexual do trabalho, vem o tema da disparidade salarial. Para verificar se isso ocorria na empresa terceirizada responsável por atender a Reitoria, entramos em contato com uma pessoa ligada à empresa, visando esclarecer esse tópico em especial. Naquele momento fomos informadas/os que o único homem encarregado da limpeza na Reitoria 
havia sido demitido. Todavia, de acordo com essa pessoa, não havia diferença de salário quando algum homem era empregado. Não pudemos confirmar a informação, verificando, por exemplo, se as mulheres tinham mais descontos salariais, porque não tivemos contato com homens que trabalharam com a limpeza da Reitoria.

Neste ponto, cabe retomar a fala da interlocutora citada neste texto, sobre ser difícil para um pai de família conseguir trabalhar pelo salário de R $\$$ : 803,00. Na contemporaneidade, embora muitas mulheres trabalhem fora e por vezes sustentem sozinhas as suas famílias, o trabalho feminino é usualmente visto como secundário; como um complemento da renda principal. Laís Abramo (2007) defende em sua tese que existe uma constituição e reprodução da noção das mulheres como uma força de trabalho secundária na sociedade. Para a autora, essa noção implica que a atividade profissional das mulheres na esfera pública está ligada às funções que elas assumem no âmbito privado. Isto posto, Abramo estuda a permanência do que ela chama de imagens de gênero.

Pensando nisso, fomos ao questionário, no qual dezessete mulheres responderam que seus salários eram fundamentais para a renda da família. Nossos dados apontam que em $81 \%$ dos casos, uma ou duas pessoas contribuíam com a renda familiar, o que invariavelmente as coloca em um papel importante, como mostra o gráfico a seguir: 


\section{Quantas pessoas contribuem com a renda familiar?}



Como no momento da criação do questionário não aprofundamos tanto a questão do gênero, não é possível saber se o salário delas é a principal fonte de renda. Concluímos apenas que é imprescindível que a maior parte delas trabalhe.

\section{A Terceirização e a precarização do trabalho}

Do levantamento bibliográfico sobre gênero, trabalho e precarização feito para esse estudo, aparece com frequência o tema da terceirização das funções ocupadas pelas mulheres. Nesta pesquisa, entendemos que a precarização do trabalho e terceirização estão diretamente ligadas entre si e também podem estar ligadas às questões de gênero. Antes de entrar numa discussão mais profunda, no entanto, começaremos explicando o cenário deste fenômeno e como a terceirização ocorre no caso em questão. 
A terceirização, tão presente na contemporaneidade, ganhou espaço a nível macro como um dos resultados da reestruturação produtiva que ocorreu em diversos países. Segundo Antunes (1999), a partir dos anos setenta há uma crise no padrão de acumulação taylorista/fordista, que expressava uma crise estrutural do capital. Nesse contexto, a reestruturação produtiva provocou transformações profundas no trabalho, através da acumulação flexível, do downsizing, da tecnologia mais avançada e principalmente da implementação do modelo toyotista. Antunes considera que houve um conjunto de elementos de continuidades e de descontinuidades no padrão da acumulação flexível, sendo uma das consequências a desconcentração produtiva e, portanto, a criação de empresas terceirizadas. O estudioso prossegue:

\begin{abstract}
Algumas das repercussões dessas mutações no processo produtivo têm resultados imediatos no mundo do trabalho: desregulamentação enorme dos direitos do trabalho, que são eliminados cotidianamente em quase todas as partes do mundo onde há produção industrial e de serviços; aumento da fragmentação no interior da classe trabalhadora; precarização e terceirização da força de trabalho humana que trabalha (...). ANTUNES, 1999, p. 53.
\end{abstract}

Como é possível notar, a flexibilização do trabalho geralmente está ligada a uma série de elementos negativos para os trabalhadores e as trabalhadoras, os quais configuram o trabalho precário. Esses 
elementos estiveram presentes na pesquisa, quando verificamos, primeiramente, que era o trabalho de limpeza era terceirizado, que havia alta rotatividade, grandes descontos salariais e a diminuição dos direitos em relação às empresas que contratam diretamente os funcionários e as funcionárias. Retomaremos esse tópico após a explicação mais específica da terceirização, aspecto fundamental para a compreensão da precarização.

No Brasil a reestruturação teve início a partir de transformações políticas e econômicas; ocorreu em meados dos anos noventa e prevalece até então. Esse fenômeno é perceptível quando se nota que os serviços que eram realizados pelas próprias instituições passam a ser terceirizados, como o caso da limpeza na Reitoria da UFPR. Segundo Souza (2011),

A terceirização, como é chamada no Brasil, caracteriza-se pelo ato de repassar determinados serviços ou etapas do processo produtivo a outras empresas. Embora esta prática exista desde o início do processo de industrialização, ela não possuía a centralidade e importância adquirida a partir de 1970 em países de capitalismo avançado e 1990 no Brasil. Desde então, a terceirização constitui uma das práticas do processo de reestruturação produtiva, de que são características a busca por flexibilização do trabalho e da produção. (SOUZA, p. 50)

As empresas terceirizadas cujos serviços de limpeza são contratados pela UFPR, permanecem na instituição durante um prazo de 
cinco anos. Isso não implica, porém, na substituição das trabalhadoras da limpeza durante as transições. Conversamos com serventes que trabalhavam nesse campus havia mais de cinco anos, mas constatamos que elas eram parte da exceção, pois a rotatividade das funcionárias é elevada. Quinze das respondentes trabalhavam na empresa há menos de dois anos. Segundo a nossa interlocutora, as funcionárias nunca pediam demissão. A justificativa era a de que elas eram demitidas pela empresa porque "falta demais, não faz o serviço direito. Um bom funcionário a empresa fica". A alta rotatividade pode ser considerada uma das características da precarização dos trabalhos terceirizados. Ainda segundo Souza (2011),

O que se constata é que em muitos casos a terceirização se torna sinônimo de precarização do trabalho e do emprego, pois a diminuição de benefícios sociais, de salários e de contratos de trabalho formais constituem as próprias características dessa forma de organização da produção e do trabalho. (SOUZA, p. 61)

Cabe lembrar que muitas trabalhadoras relataram ter descontos salariais frequentes por faltas, as quais elas deviam repor nos fins de semana. Isso indica que além da justificativa para os descontos e de mais trabalho, também é a explicação da empresa para as demissões.

Outra características citada sobre a terceirização é a flexibilização do trabalho. Foi possível observar tal elemento nos dois turnos das funcionárias, sendo que o primeiro começava às 06:30 horas 
da manhã e o segundo encerrava às 22:30 horas. $\mathrm{O}$ fato de que os turnos começavam muito cedo ou acabavam muito tarde foi entendido como uma precarização do trabalho delas, por questões de segurança e de qualidade de vida. Dezenove das participantes moravam na região metropolitana e havia três em Curitiba, que moravam em bairros afastados do centro: Vila Sandra e Bairro Alto. Isso demonstra que elas precisam de uma quantidade considerável de tempo para chegar até o trabalho ${ }^{8}$. Uma delas, por exemplo, relata que precisava sair de casa às quatro horas da madrugada para bater o ponto no horário. No entanto, muitas citaram que o horário era um ponto positivo, porque assim elas podiam buscar os filhos e filhas na escola e realizar outras tarefas. É relevante citar que todas elas eram mães. Essa avaliação delas sobre o horário de trabalho deixa bastante clara, mais uma vez, a relação entre trabalho, precarização e gênero, pois a função de cuidar das crianças é predominantemente atribuída às mães.

O trabalho terceirizado na limpeza costuma ser intensivo e rotineiro; ser um trabalho manual. Ora, a ocupação das serventes da limpeza ilustra muito bem esse fator: quase todas seguem uma rotina diária, têm sempre as mesmas salas, banheiros e andares para limpar.

Enquanto conversávamos com as trabalhadoras, foi frequente nos depararmos com um discurso de que o trabalho delas era digno, em várias partes do questionário. Raquel, por exemplo, em resposta à pergunta "o que você mais gosta no seu trabalho?" disse que não tinha

\footnotetext{
${ }^{8}$ Geralmente de transporte público.
} 
que gostar ou não gostar da profissão dela, o que importava é que era um serviço digno. As trabalhadoras também afirmaram que não tinham vergonha de seu trabalho, em diferentes questões que não necessariamente estavam atreladas a essa temática. Durante a conversa com Carmem, ela disse: "não tenho vergonha de dizer que fui zeladora". Já Márcia, durante a participação na pesquisa, afirmou: "não tenho vergonha de trabalhar com limpeza, o importante é não roubar. As pessoas precisam da gente". Entendemos que essas posturas expressam que elas reconhecem que a sua profissão é socialmente desvalorizada.

Do mesmo modo, a maior parte delas não fazia críticas à profissão e à condição de terceirizada. Apenas uma funcionária mencionou que as condições de trabalho eram piores em virtude da terceirização e que se sentia desvalorizada, pois o seu trabalho era muito importante para a universidade e era incoerente com o salário tão baixo, a pressão para não faltar e por fazer um bom trabalho. Ela acreditava que se tivesse sido contratada diretamente pela UFPR, teria condições melhores. Na questão "o que você acha das suas condições de trabalho?", quatorze das participantes as julgaram boas. Foi comum ouvir relatos de que por conta da baixa escolaridade, elas não conseguiriam algo melhor, por isso diziam que não podiam reclamar. Em geral, elas disseram que os estudantes e professores as tratavam bem e que gostavam do ambiente da universidade, mas não 
frequentavam nenhum espaço fora do período de trabalho, exceto o Restaurante Universitário.

Embora a avaliação das condições do trabalho tenha sido positiva, bem como o contato com as pessoas que frequentam a universidade, $48 \%$ das trabalhadoras afirmaram pretender mudar de área, um número consideravelmente elevado.

\section{Considerações Finais}

Este artigo buscou mostrar alguns dos principais aspectos do trabalho das profissionais da limpeza da Reitoria UFPR, através de um diálogo entre os resultados do questionário, o levantamento bibliográfico e as reflexões em campo para construir um objeto sociológico. Primeiramente, partindo do perfil das trabalhadoras, foi verificada a importância que elas atribuem às relações sociais. Além disso, constatamos que o fato de a maioria das funcionárias ser casada, mais velha e ter filhos acompanha uma tendência verificada a partir dos anos oitenta no Brasil.

$\mathrm{Na}$ sequência, a relação entre gênero e trabalho nesse tipo de ocupação foi abordada, partindo das noções de feminino e masculino trazidas em campo e presentes no imaginário social. De acordo com o que foi observado nessa e em outras pesquisas citadas, prevalece entre elas uma ideia tradicional dos papéis dos homens e das mulheres: ao homem cabe ser chefe de família, o provedor, enquanto a mulher se 
atenta ao privado, ao doméstico. A partir de então, houve a inserção da discussão sobre a divisão sexual do trabalho, sempre aliada das informações de conversas e da aplicação do questionário. Abordamos tal conceito e os seus desdobramentos possíveis, como, por exemplo, a bipolaridade da inserção das mulheres no mercado de trabalho. Se por um lado as de maior qualificação estão conquistando mais espaços, as de estratos sociais mais baixos e sem qualificação formal permanecem em trabalhos precários, associados à noção de características que seriam "naturalmente" femininas. As trabalhadoras da UFPR se enquadram no segundo polo, tendo por vezes ocupado funções ligadas ao privado e ao doméstico. Além disso, foram indicadas por outras mulheres e se tinham parentes que trabalhavam na limpeza, eram quase sempre mulheres.

O texto avançou com o tema da terceirização. Conforme vimos, a terceirização tem sido mais frequente no país a partir dos anos noventa. Essa forma prestar serviços prega a flexibilização do trabalho e, consequentemente, implica horários diferenciados, descontos salariais frequentes e menos direitos. A rotatividade é elevada, sendo que no universo de pesquisa, quinze funcionárias estavam na empresa há menos de dois anos. Apesar disso, várias trabalhadoras disseram que o horário, por exemplo, era uma vantagem, tendo em mente atribuições que remetem novamente ao privado e ao papel de mães.

Por fim, foi identificado um discurso sempre presente defendendo que o trabalho era digno e que elas não tinham vergonha de 
sua ocupação, mesmo quando esses temas não eram colocados em pauta. Com isso, entendemos que elas percebiam que o seu trabalho era desvalorizado socialmente, acionando um discurso de defesa. A avaliação do ambiente, das pessoas e das condições de trabalho foi positiva na maior parte dos questionários. Esse dado foi relacionado ao fato de a maioria das funcionárias relatar que, por conta da escolaridade baixa, não conseguiriam coisa melhor, portanto não poderiam reclamar de seu emprego; no entanto, dez trabalhadoras disseram desejar mudar de área.

Foram explorados elementos que de acordo com o campo e o embasamento teórico, pareceram mais propícios à investigação sociológica. Contudo, no artigo não foi possível analisar profundamente todas esferas passiveis de serem pesquisadas, como o tema étnicoracial. Esperamos que essa pesquisa enseje mais debates sobre o assunto e possibilite que tais questões sejam estudadas e que novas sejam colocadas.

\section{Referências}

ABRAMO, Laís Wendel. A inserção da mulher no mercado de trabalho: uma força de trabalho secundária? Tese (Sociologia) 327p. Departamento de Sociologia, Faculdade de Filosofia, Letras e Ciências Humanas, Universidade de São Paulo. São Paulo, 2007. 
ANTUNES, Ricardo. Os sentidos do trabalho: ensaio sobre a afirmação e negação do trabalho. São Paulo: Boitempo editorial, 1999.

ARAÚJO, A. M. C. Trabalho, Precarização e Relações de Gênero em Tempos de Flexibilização e Reestruturação Produtiva. 2007.

BRUSCHINI, C. LOMBARDI, M.R. Instruídas e trabalhadeiras, trabalho feminino no final do século XX. Cadernos Pagu (17/18) 2001/02: pp.157-196.

CELEGUIM e ROESLER, A invisibilidade social no âmbito do trabalho. Revista Científica da faculdade das américas, Ano III. 2009.

CHAVES, M. N. Terceirização dos serviços de limpeza: vivências de sofrimento de mulheres negras trabalhadoras diante do trabalho. In: II Simpósio Nacional sobre Democracia e Desigualdades, 2014, Brasília. Anais do II Simpósio Nacional sobre Democracia e Desigualdades. Brasília: UnB, 2014.

GITAHY, L. M. C., SILVA, N. S.. Reestruturación productiva y división sexual del trabajo em la indústria brasilenã de línea blanca. Diversidad Cultural, género y tecnologia: um abordaje interdisciplinario. (CEFET/PR). p. 45-63, 2006. 
HIRATA, H., KERGOAT, D. Novas configurações da divisão sexual do trabalho. Cadernos de Pesquisa, v. 37, n. 132, p. 595-609, set./dez. 2007.

IBGE. Síntese de indicadores sociais: uma análise das condições de vida da população brasileira. 2010. Disponível em: http://www.ibge.gov.br/home/estatistica/populacao/condicaodevida/indi cadoresminimos/sinteseindicsociais2010/SIS_2010.pdf acesso: 18/07/2014.

KERGOAT, Danièle. Dinâmica e consubstancialidade das relações sociais. Revista Novos Estudos, CEBRAP nº 86, 2010.

LE BRETON, David. A sociologia do corpo. 6. ed. Petropolis: Vozes, 2012. $102 \mathrm{p}$.

NOGUEIRA, C. M. . As Metamorfoses da Divisão Sexual do Trabalho. In: Vera Lúcia Navarro; Valquíria Padilha. (Org.). Retratos do Trabalho no Brasil. 1ed.Uberlândia - MG: Editora da Universidade Federal de Uberlândia, 2009, v. 1, p. 63-78.

SOUZA, Tatiele Pereira. Identidade e subalternidade [manuscrito]: a construção da identidade de trabalhadores serventes de limpeza/ TatielePereira de Souza. - 2011. 224 f. 